\title{
Correlation Analysis of Infraorbital Foramen with Related Anatomical Structures
}

\author{
Análisis de Correlación del Foramen Infraorbitario con Estructuras Anatómicas Relacionadas
}

\author{
Nazli Gulriz Ceri $^{1} \&$ Eda Duygu Ipek ${ }^{1}$
}

CERI, N. G. \& IPEK, E. D. Correlation analysis of infraorbital foramen with related anatomical structures. Int. J. Morphol., 38(4):914918, 2020.

SUMMARY: The anatomical localization of foramen infraorbitale (FOI) and its relationship with ambient structures are of great importance for clinicians and surgeons. This study was performed on seventy five skulls, and the distance between FOI to important anatomical formations, angular position of the zygomatic bone and the relationship between these parameters were investigated on both sides. The distance of FOI to margo infraorbitalis (MI), apertura piriformis (AP) and spina nasalis anterior (SNA), upper face height (UH) and upper face width (UW) were measured. Zygomatic bone triangle angles (SA, PA, IA) and porion-nasion-spina nasalis anterior angle (PNS) were measured from lateral view of the skull. While there was no significant difference between right and left measurement except for PA ( $\mathrm{p}=0.03$ ), the distance from FOI to MI is showed a very high degree positive correlation between the right and left sides, the distance from the FOI to AP was weak correlated only right side.

KEY WORDS: Skull; Infraorbital foramen; Morphometry; Face; Infraorbital nerve; Infraorbital vessels.

\section{INTRODUCTION}

Foramen infraorbitale (FOI) is located approximately $1 \mathrm{~cm}$ below the margo infraorbitalis on the anterior aspect of the maxillary bone in midface (Singh, 2011; Elseikh et al., 2013; Varshney \& Sharma, 2013; Singh et al., 2015; Nanayakkara et al., 2016; Saheb, 2017; Tewari et al., 2018), infraorbital nerve and vessels that come from sulcus infraorbitalis and canalis infraorbitalis in orbita floor, respectively, passes through it (Rajeswari et al., 2016; Srinisha et al., 2018; Tewari et al.). Infraorbital nerve divided into four branches which sensorial innervate the midface region; lower eyelid, superior lip, ala of the nose, cheek, labial gum, upper jaw teeth and gingiva (Singh; Shaik et al., 2012; Singh et al.; Karpagam \& Thenmozhi, 2016; Veeramuthu et al., 2016; Ananya et al., 2019).

Infraorbital nerve anesthesia is commonly used in various surgical operations including midface region and paranasal sinus surgery (Bjelakovic et al., 2017; Ananya et al.) and FOI is considered an important surgical parameter for external access to the maxillary sinus (Martins-Júnior et al., 2017) and is used as an acupuncture point in the treatment of trigeminal neuralgia that does not respond to pharmacological treatment (Ilayperuma et al., 2010; Singh; Karpagam \& Thenmozhi; Tewari et al.). Accurate knowledge of FOI localization provides risk free treatment of zygomatic bone fractures (Srinisha et al.) and is also important in midface augmentation surgery using malar, submalar, paranasal implants (Raschke et al., 2013). Infraorbital nerve block forms the basis of pain management in cleft lip surgery (Varshney \& Sharma) and provides excellent analgesia to perform biopsies, scar revisions, simple lacerations, maxillofacial procedures, as well as various endoscopic and cosmetic cutaneous procedures (Shaik et al.).

Structures surrounding the FOI such as malar prominence of the zygomatic bone, proximity to the orbita, disturb the clinician when anesthetizing. It is reported that dentists do not prefer FOI anesthesia because they are afraid of damaging the patient's eye (Tewari et al.). Iatrogenic injury of the infraorbital neurovascular bundle may result in bleeding, hypoesthesia, anesthesia or paraesthesia in the innervated areas (Bjelakovic et al.). In one study, it has been reported that $23 \%$ of patients who have undergone malar implant surgery, suffer from dysthesis (Raschke et al.).

${ }^{1}$ Department of Anatomy, Aydin Adnan Menderes University, Faculty of Medicine, Aydin, Turkey. 
The zygomatic bone is found in the lateral part of the skull and plays an important role in facial asymmetry and formation of the characteristic features of the midface region along with the maxilla (Wu \& Bräuer, 1993). The inclination of the zygomatic bone against the Frankfurt horizontal plane is one of the racial diagnostic features in the anthropological characterization of the individual. It is reported that Caucasoid and Negroid skulls have receded zygomas whereas Mongoloids have a projecting zygomas (Durbar, 2014). Therefore, the angle of inclination of the zygomatic bone is higher in Mongoloids. Zygomaticomaxillary suture is also used in race identification in forensic medicine (Sholts \& Wärmländer, 2012).

Detailed knowledge of the precise anatomical location and the possible variations of the FOI is fundamental to ensure safe and successful regional anaesthesia and to avoid the risk of damaging the neurovascular bundle (Ilayperuma $e t$ al.; Shaik et al.; Gnanagurudasan et al., 2014; Singh et al.). Furthermore, the FOI position helps to identify the infraorbital plexus region, which is believed to be a risk site during plastic surgery (Singh; Veeramuthu et al.; Ananya et al.). To ascertain its precise location, various soft tissue and bone landmarks have been utilized in several studies and the results showed a wide variation (Elias et al., 2004; Ilayperuma et al.; Panicker et al., 2016; Veeramuthu et al.; Ananya et al.). Zygomatic bone may be related to these variations which is responsible for asymmetry of the midface region and shows different morphological features between races and even within the same race.

The aim of the present study was to investigate the relationship between localization of infraorbital foramen and surrounding structures and angular evaluation of zygomatic bone position.

\section{MATERIAL AND METHOD}

This study was carried out on seventy five adult skulls of unknown sex and age obtained from the anatomy department laboratory of Aydin Adnan Menderes University, Faculty of Medicine. The inclusion criteria of the study was determined as the absence of structural or acquired deformity and variations in the skulls. The skulls were placed on a standard plane and photographed from the norma facialis and norma lateralis using a professional digital camera (Nikon ${ }^{\circledR}$ - modelD5300) set for automatic capture which was placed on a tripod. Then measurements were realized on the images using Imagej ${ }^{\circledR}$ software, version 1.47.
In this study, three parameters were measured morphometrically on both sides; vertical distance from the center of FOI to margo infraorbitalis (FOI_MI), the horizontal distance from the center of FOI to apertura piriformis (FOI_AP) and the distance from the center of FOI to spina nasalis anterior (FOI_SNA). Upper face height (FH); the distance from the root of the nose (nasion) to the base of the nose (subnasion) and upper face width $(\mathrm{FW})$ is the maximal distance between the most lateral points of the zygomatic arches, were measured shown in Figures 1 and 2.

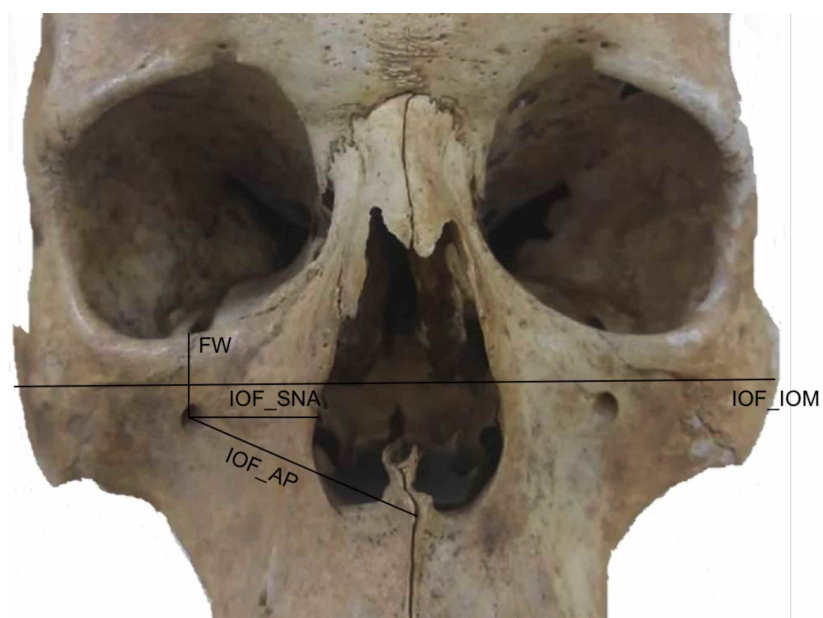

Fig. 1. FOI_MI; the distance of infraorbital foramen to margo infraorbitalis, FOI_AP; the distance of infraorbital foramen to apertura piriformis, FOI_SNA; the distance of infraorbital foramen to spina nasalis anterior, FW; upper face width..

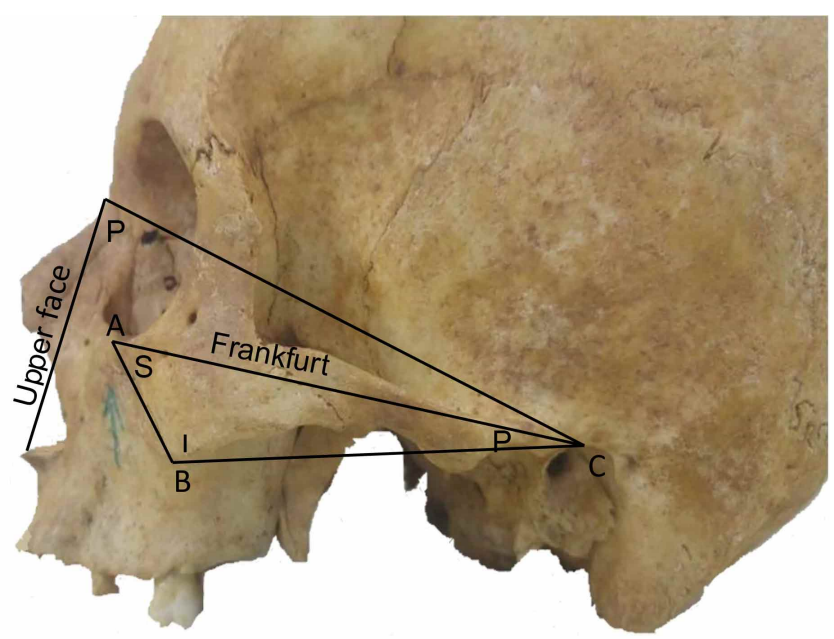

Fig. 2. ABC triangle; zygomatic bone triangle; The upper edge of the zygomatic bone triangle forms the horizontal Frankfurt plane, PNS; porion-nasion-spina nasalis anterior angle, SA; tilt of the zygomatig bone also the superior angle of the triangle, PA; posterior angle of the triangle, IA; inferior angle of the triangle, FH; upper face height. 
In addition, the relationship between infraorbital foramen localization and zygomatic bone, which plays an important role in the anthropological characterization of the midface, was investigated. The angle between the porionnasion-spina nasalis anterior (PNS) and the tilt angle of the zygomatic bone against the Frankfurt horizontal plan (SA) were measured on both sides. As shown in Figure 2, the lower end of the line passing through the upper and lower points of zygomaticomaxillary suture was combined with the Frankfurt horizontal plan at the porion to form the zygomatic bone triangle and the posterior (PA) and inferior (IA) angle of the triangle was recorded.

Table I. Average values of measured parameters. All parameters are presented as mm. ss; standard deviation.

\begin{tabular}{lcc}
\hline \multicolumn{2}{c}{ Mean \pm ss } \\
FH & \multicolumn{2}{c}{$50.98 \pm 3.57$} \\
\hline FW & \multicolumn{2}{c}{$134.08 \pm 4.62$} \\
\hline \multicolumn{3}{c}{ Left } \\
\hline FOI_MI & $6.32 \pm 1,5$ & $6.75 \pm 1.54$ \\
FOI_AP & $17.9 \pm 2,45$ & $18.23 \pm 1.8$ \\
FOI_SNA & $33.88 \pm 3,36$ & $32.98 \pm 2.48$ \\
PNS & $86.07 \pm 5,48$ & $88.12 \pm 5.23$ \\
SA & $60.33 \pm 6,89$ & $61.34 \pm 6.04$ \\
PA & $16.61 \pm 2,64$ & $15.65 \pm 2.19$ \\
IA & $103.04 \pm 7,44$ & $105.03 \pm 6.89$ \\
\hline
\end{tabular}

The correlation of these parameters with each other, and whether there was a meaningful difference between the right and left sides was evaluated. Firstly, the normality of the data was evaluated by the Kolmogorov-Smirnov test. Paired t test was used to compare the parameters between sides and the correlation for each measurements determined by Pearson's correlation test.

\section{RESULTS}

A total of seventy five skulls were used for this study, The average values of the measured parameters are shown in Table I.

According to t test results, no significant difference was found between right and left measurements of any parameters $(\mathrm{p}>0.05)$ except for the PA $(\mathrm{p}=0.03)$.

While the FOI_MI distance on both sides showed a high positive correlation, only a weak positive correlation was found between the FOI and AP on the right side (Table II). As shown in Table III, only a weak positive correlation was found between FOI and PA on both sides.

Table II. Correlation analysis of IOF on both sides, Pearson's correlation coefficient (Sig. two tailed); r, r $<0,2$ very weak correlation, $\mathrm{r}=0,2-0,4$ weak correlation $(*), \mathrm{r}=0,4-0,6$ moderate correlation $(* *), \mathrm{r}=0,6-0,8$ high correlation $(* * *)$, $\mathrm{r}>0,8$ very high degree correlation $(* * * *), \mathrm{r}$; right side, 1 ; left side.

\begin{tabular}{lllllll}
\hline & FOI_MIr & FOI_APr & FOI_SNAr & FOI_MIl & FOI_AP1 & FOI_SNAl \\
\hline FOI_Mir & 1 & $0.27^{*}$ & 0.07 & $0.84 * * * *$ & 0.18 & 0.009 \\
FOI_Apr & $0.27 *$ & 1 & $0.62^{* * *}$ & 0.22 & $0.64 * * *$ & $0.49^{* *}$ \\
FOI_SNAr & 0.07 & $0.62^{* * *}$ & 1 & 0.1 & $0.21^{*}$ & $0.8^{* * * *}$ \\
FOI_M1 & $0.84^{* * * *}$ & 0.22 & 0.1 & 1 & 0.18 & 0.03 \\
FOI_Apl & 0.18 & $0,64^{* *}$ & $0.21^{*}$ & 0,18 & 1 & $0.43^{* *}$ \\
FOI_SNAl & 0.09 & $0.49^{* *}$ & $0.8^{* * * *}$ & 0.03 & $0.43^{* *}$ & 1 \\
\hline
\end{tabular}

Table III. Correlation analysis of FOI with surrounding structures, Pearson's correlation coefficient (Sig. two tailed); $r$, r $<0,2$ very weak correlation, $\mathrm{r}=0,2-0,4$ weak correlation $(*), r=0,4-0,6$ moderate correlation $(* *), r=0,6-0,8$ high correlation $(* * *)$, $r>0,8$ very high degree correlation (****), r; right side, 1; left side.

\begin{tabular}{lllllllll}
\hline & FOI_MIr & FOI_APr & FOI_SNAr & FOI_MIl & FOI_APl & FOI_SNAl & FH & FW \\
\hline F H & 0.11 & $0.32^{*}$ & $0.45^{* *}$ & 0.12 & 0.18 & $0.3^{*}$ & 1 & $0.45^{* *}$ \\
FW & 0.05 & 0.14 & $0.47^{* *}$ & 0.08 & 0.1 & $0.37^{*}$ & $0.45^{* *}$ & 1 \\
S Ar & 0.14 & 0.1 & 0.08 & 0.15 & 0.12 & 0.07 & 0.02 & $-0.26^{*}$ \\
S Al & 0.11 & 0.12 & 0.04 & 0.13 & 0.1 & 0.06 & 0.11 & 0.18 \\
IAr & 0.18 & 0.14 & 0.1 & 0.16 & 0.13 & 0.12 & 0.06 & $-0.26^{*}$ \\
IA1 & 0.1 & 0.16 & 0.11 & 0.1 & 0.18 & 0.04 & 0.04 & $-0.28^{*}$ \\
P Ar & $0.2^{*}$ & 0.1 & $0.29^{*}$ & $0.27^{*}$ & 0.14 & 0.07 & $0.5^{* *}$ & $0.44^{* *}$ \\
PAl & $0.34^{*}$ & $0.42^{* *}$ & 0.12 & $0.37^{*}$ & 0.13 & 0.1 & 0.18 & $0.42^{* *}$ \\
PNSr & 0.14 & 0.11 & 0.18 & 0.12 & 0.1 & 0.16 & $0.45^{* *}$ & $-0.28^{*}$ \\
P NS1 & 0.1 & 0.13 & 0.15 & 0.1 & 0.12 & 0.15 & 0.16 & 0.02 \\
\hline
\end{tabular}




\section{DISCUSSION}

Many researches have been carried out to determine the exact location of the FOI by considering its relationship with the surrounding structures and the results show wide variation between the gender and populations.

In our study, mean distance FOI_MI was $6.32 \pm 1.5$ $\mathrm{mm}$ on the right side ranging from $3.43 \mathrm{~mm}$ to $12.46 \mathrm{~mm}$ and $6.75 \pm 1.54$ on the left side ranging from $3.4 \mathrm{~mm}$ to 12.86 $\mathrm{mm}$. Singh et al. similarly reported that the FOI_MI distance was distributed over a wide range of 3.5 to $10.4 \mathrm{~mm}$ on the right side and 3.7 to $10.3 \mathrm{~mm}$ on the left side. Our mean values are close to the Elias et al., Elsheikh et al. (2013), Panicker et al., Singh et al., Saheb, Martins-Júnior et al., Tewari et al., Singh, Ananya et al. and Ilayperuma et al. were found FOI_MI values close to $1 \mathrm{~cm}$. Veeramuthu et al., Shaik et al., Varshney \& Sharma, Gnanagurudasan et al. FOI_MI values were slightly higher than our results. We did not find a significant difference between right and left FOI_MI measurements, but Varshney \& Sharma, MartinsJúnior et al. and Tewari et al. found difference right and left sides. Gnanagurudasan et al. found difference right and left side only male while Ilayperuma et al. found a difference between male and female on both sides. Our FOI_SNA and FOI_AP mean value was $33.88 \pm 3.36,17.9 \pm 2.45 \mathrm{~mm}$ on the right side and $32.98 \pm 2,48,18.23 \pm 1,8 \mathrm{~mm}$ on the left side, respectively. Tewari et al. found significant differences in FOI_AP between right and left side. We did not find any significant difference between the right and left measurements of any parameters except PAr and PAl. It can be predicted that PAr showed moderate correlation with FH and FW, while PAl showed moderate correlation with only FW. Also, PA showed weak correlation with FOI_MI on both sides perhaps depending on the height of the upper face.

We found a very high correlation between right and left FOI_MI measurements ( $\mathrm{r}=0.84)$, similar to MartinsJúnior et al., (r=0.8) and Singh (r=0.76). Also FOI_MI was weak correlated with FOI_APr $(r=0.27)$ in our study while Singh reported a moderate correlation on the left side $(\mathrm{r}=0.5)$. In addition, Singh found the FOI_MIr to be weakly correlated with the FOI_APl in contrast to our study. Similar to our study, Singh found a moderate correlation between the right and left FOI_AP, whereas the FOI_MIr correlated weakly with FOI_APl ( $r=0.37)$ in contrast to our study.

Contrary to our expectations, there was no correlation zygomatic bone triangle angles and PNS between the measurements which are indicating the localization of FOI. Heuzé et al. (2016) state that maxilla and premaxilla are more important than the zygomatic bone in the development of midface skeletal architecture. Also Richtsmeier (2015), reported that the zygomatic bone was resistant to severe changes in the structure of the midface bones, and facial analysis of people with craniocinocytosis results of fibroblast growth factor receptors mutation, showed that the zygomatic bone was less affected than the other midface bones. The results of our study support these findings because of FOI, which is a clinically important landmark of the midface region, does not correlate with zygomatic bone.

\section{CONCLUSION}

Until today, various bone and soft tissue landmarks were researched in order to estimate the precise location of the IOF. Significant variations are noted in the literature investigating the distance of the IOF to the surrounding structures. IOF and environmental structures of the anatomical relationships, correlations are evaluated in the literature is very important in estimating the exact location of the IOF.

We believe that the results of our study will allow clinicians to make preoperative planning and to develop anatomical landmarks by considering IOF's relationships with environmental structures. In this manner our results will contribute to the literature.

CERI, N. G. \& IPEK, E. D. Análisis de correlación del foramen infraorbitario con estructuras anatómicas relacionadas. Int. J. Morphol., 38(4):914-918, 2020.

RESUMEN: La localización anatómica del foramen infraorbitario (FIO) y su relación con las estructuras adyacentes son de gran importancia para los médicos y cirujanos. Este estudio se realizó en setenta y cinco cráneos, y se investigó la distancia entre FIO a formaciones anatómicas importantes, la posición angular del hueso cigomático y la relación entre estos parámetros en ambos lados. Se midió la distancia de FIO al margen infraorbitario (MI), apertura piriforme (AP) y espina nasal anterior (ENA), altura superior de la cara (AC) y ancho superior de la cara (AC). Los ángulos del triángulo óseo cigomático y el ángulo anterior porion-nasion-epina nasal se midieron desde la vista lateral del cráneo. Si bien no hubo una diferencia significativa entre la medición derecha e izquierda, a excepción AP $(\mathrm{p}=0,03)$, la distancia de FIP a MI mostró una correlación positiva de alto grado entre los lados derecho e izquierdo, la distancia de FIO a AP fue débil correlacionado solo en el lado derecho.

PALABRAS ClAVE: Cráneo; Foramen infraorbitario; Morfometría; Cara; Nervio infraorbitario; Vasos infraorbitarios. 


\section{REFERENCES}

Ananya, B.; Sangeetha, S. \& Premavathy, D. Morphometric study of the infraorbital foramen in local anesthesia. Drug Interv. Today, 12(6):12479, 2019.

Bjelakovic, M. D.; Popovic, J.; Stojanov, D.; Dzopalic, T. \& Ignjatovic, J. Morphometric characteristics of the infraorbital foramen on volumerendered CT scans. Radiat. Appl., 2(3):204-9, 2017.

Durbar, U. S. Racial variations in different skulls. J. Pharm. Sci. Res., $6(11): 370-2,2014$.

Elias, M. G.; Silva, R. B.; Pimentel, M. L.; Cardoso, V. T. S.; Rivello, T. \& Babinski, M. A. Morphometric analysis of the infraorbital foramen and acessories foraminas in Brazilian skulls. Int. J. Morphol., 22(4):273-8, 2004.

Elsheikh, E.; Nasr, W. F. \& Ibrahim, A. A. S. Anatomical variations of infraorbital foramen in dry human adult Egyptian skulls, anthropometeric measurements and surgical relevance. Otorhinolaryngol. Clin. Int. J., 5(3):125-9, 2013.

Gnanagurudasan, E.; Ahamed, S. R.; Deepalaxmi, S. \& Gnanadesigan, E. A genderwise study on the morphometry of infraorbital foramen and its laterality in dry adult Skulls of South Indian populations. Int. J. Med. Sci. Public Health, 3(5):546-8, 2014.

Heuzé, Y.; Kawasaki, K.; Schwarz, T.; Schoenebeck, J. J. \& Richtsmeier, J. T. Developmental and evolutionary significance of the zygomatic bone. Anat. Rec. (Hoboken), 299(12):1616-30, 2016.

Ilayperuma, I.; Nanayakkara, N. \& Palahepitiya, N. Morphometric analysis of the infraorbital foramen in adult Sri Lankan skulls. Int. J. Morphol., 28(3):777-82, 2010

Karpagam, G. N. \& Thenmozhi, M. S. A study of morphometric analysis of infraorbital foramen in South Indian dry skulls. J. Pharm. Sci., 8(11):1318-9, 2016.

Martins-Júnior, P. A.; Rodrigues, C. P.; De Maria, M. L.; Nogueira, L. M.; Silva, J. H. \& Silva, M. R. Analysis of anatomical characteristics and morphometric aspects of infraorbital and accessory infraorbital foramina. J. Craniofac. Surg., 28(2):528-33, 2017.

Nanayakkara, D.; Peiris, R.; Mannapperuma, N. \& Vadysinghe, A. Morphometric analysis of the infraorbital foramen: the clinical relevance. Anat. Res. Int., 2016:7917343, 2016.

Panicker, J. I.; Kumar, V. \& Veerannasetty, V. K. Anthropometric analysis of infraorbital foramen in adult Indian dry skull. Nittle Univ. J. Health Sci., 6(2):27-30, 2016.

Rajeswari, K.; Rohinidevi, M.; Vimala, V. \& Megala, D. Morphometric analysis of infraorbital foramen in human dry skulls. Int. J. Anat. Res., 4(3):2725-9, 2016.

Raschke, R.; Hazani, R. \& Yaremchuk, M. J. Identifying a safe zone for midface augmentation using anatomic landmarks for the infraorbital foramen. Aesthet. Surg. J., 33(1):13-8, 2013.

Richtsmeier, J. Developmental and evolutionary significance of the zygomatic bone. FASEB J., 29(1 Suppl.), 2015. Available from: https:/ /www.fasebj.org/doi/abs/10.1096/fasebj.29.1_supplement.212.3

Saheb, S. H. A study on position of infraorbital foramen. Int. J. Anat. Res., 5(3.2):4257-60, 2017

Shaik, H. S.; Shepur, M. P.; Desai, S. D.; Thomas, S. T.; Maavishettar, G. F. \& Haseena, S. Morphometric analysis of Infra orbital foramen position in South Indian skulls. Indian J. Innov. Dev., 2:1-4, 2012

Sholts, S. B. \& Wärmländer, S. K. Zygomaticomaxillary suture shape analyzed with digital morphometrics: reassessing patterns of variation in American Indian and European populations. Forensic Sci. Int., 217(13):234.e1-e6, 2012.

Singh, A.; Agarwal, P.; Singh, N. \& Debberma, S. Accessory infraorbital foramen and morphometric localization of infraorbital foramen in North Indian region. Natl. J. Integr. Res. Med., 6(5):28-33, 2015.

Singh, R. Morphometric analysis of infraorbital foramen in Indian dry skulls. Anat. Cell Biol., 44(1):79-83, 2011.
Srinisha, M.; Babu, K. Y. \& Mohanraj, K. G. Anthropometric measurement and variations in positions of infraorbital foramen and its surgical importance. Drug Interv. Today, 10(12):2462-4, 2018.

Tewari, S.; Gupta, C.; Palimar, V. \& Kathur, S. G. Morphometric analysis of infraorbital foramen in South Indian dry skulls. Bangladesh J. Med. Sci., 17(4):562-6, 2018.

Varshney, R. \& Sharma, N. Infraorbital foramen - Morphometric study and clinical application in adult Indian skulls. Saudi J. Health Sci., 2(3):1515, 2013.

Veeramuthu, M.; Varman, R.; Shalini \& Manoranjitham Morphometric analysis of infraorbital foramen and incidence of accessory foramen and its clinical implications in dry adult human skull. Int. J. Anat. Res., 4(4):2992-3000, 2016.

Wu, X. \& Bräuer, G. Morphological comparison of archaic Homo sapiens crania from China and Africa. Z. Morphol. Anthropol., 79(3):241-59, 1993.

\author{
Corresponding author: \\ Nazli Gulriz Ceri \\ Department of Anatomy \\ Faculty of Medicine \\ Aydin Adnan Menderes University \\ Aydin \\ TURKEY
}

Email: ngceri@adu.edu.tr

Received: 14-10-2019

Accepted: 09-02-2020 